\title{
Tokat İlinde Üniversite Hastanesi Kadın Hastalıkları ve Doğum Polikliniğine başvuran Gebelerde İdrar Yolu Enfeksiyonu: Üç- Yıllık Değerlendirme
}

\author{
Urinary tract infections in pregnants who were addmitted University Hospital Obstetric \\ and Gyneacology Outpatient Clinics in Tokat TURKEY: Evalıuation of three years
}

\section{Asker Zeki ÖZSOY', Mehmet Can NACAR², Bülent ÇAKMAK', Hatice YILMAZ DOĞRU1, illhan Bahri DELIBAŞ${ }^{1}$, Çiğdem KUNT ișGÜDER ${ }^{1}$, Selim GÜLÜCÜ1}

1 Gaziosmanpaşa Üniversitesi Tıp Fakültesi Kadın Hastalıkları ve Doğum AD, Tokat

2 Tokat Devlet Hastanesi Kadın Hastalıkları ve Doğum, Tokat

\section{ÖZET}

Amaç: Bu çalışmada, Tokat İlinde Üniversite Hastanesi Kadın Has talıkları ve Doğum kliniğine başvuran gebelerde idrar yolu enfeksiyonu görülme sıklığının incelenmesi ve idrar kültüründe üreme saptanan mikroorganizmaların tespit edilmesi amaçlanmıştır

Gereç ve Yöntemler: Tokat Gaziosmanpaşa Üniversitesi Kadın Hastalıkları ve Doğum kliniğine Ocak 2012- Haziran 2015 tarihleri arasındaki yaklaşık 3.5 yıllık dönemde başvuran gebelerde idrar yolu enfeksiyonu görülme sıklığı ve üreyen ajan patojenler incelenmiştir. Tam idrar tetkiki hastanemiz biyokimya laboratuarında ve idrar kültürü analizleri hastanemiz mikrobiyoloji laboratuarında değerlendirilmiştir. Elde edilen sonuçların otomasyon sistemi üzerinden retrospektif olarak ulaşılması ile verilerimiz tespit edilmiştir.

Bulgular: Hastanemize Ocak 2012 ve Haziran 2015 tarihleri arasında başvuran 2245 gebe hasta çalışmaya dahil edilmiştir. Çalışmaya alınan hastaların $(n=2245)$ yaş ortalaması $28.0 \pm 5.63$ (min:16, maks:45) olup, \%86.5'i ( $n=1942) 35$ yaş altında, \%13.5'i ( $n=303) 35$ yaş ve üzerindedir. Hastaların \%36.5'inde ( $n=819)$ gebelikte idrar yolu enfeksiyonu olduğu saptanmıştır. 35 yaş altındaki hastaların \%37.3'ünde $(n=725)$ idrar yolu enfeksiyonu saptanırken, 35 yaş ve üzerindeki hastalarda bu oran \%31.0'dir $(n=94)(p<0.05) .35$ yaş altında gebe olmak idrar yolu enfeksiyonu geçirme açısından, 35 yaş ve üzerinde gebe olmayana göre 1.3 kat daha riskli bulunmuştur ( $\mathrm{OR}=1.32 ; \mathrm{Cl}=1.02-1.72)$.

Sonuç: İdrar yolu enfeksiyonu gebelikte en önemli ve en sık görülen hastalıklar arasında yer almaktadır. Tedavi edilmeyen enfeksiyon ile preterm eylem ve buna bağlı komplikasyonlar arasında yakın ilişki mevcuttur. Gebelerde idrar yolu enfeksiyonu tedavi edilmesi ve gözardı edilmemesi gereken hastalıklardan biridir.

Anahtar Kelimeler: IYE, Gebelik, Preterm eylem

\section{ABSTRACT}

Aim: To review the frequency of urinary tract infection in pregnant women who admitted to Obstetrics and Gynecology Policlinics of University Hospital in Tokat, and to determine the identification of specific microorganisms in those with positive urine cultures.

Material and Methods: Incidence of urinary tract infection and pathogen microorganisms in pregnant women who admitted to the Obstetrics and Gynecology policlinics of Gaziosmanpasa University between January 2012 and June 2015 for about 3.5 years were investigated. Complete urinalyses and urine cultures were assessed in Biochemistry and Microbiology laboratories of our hospital, respectively. Data pertaining to test results were collected through the data automation system retrospectively.

Results: 2245 pregnant women, who were admitted to our hospital between January 2012 and June 2015, were included in our study. Median age of our study population ( $n=2245)$ was $28.0 \pm 5.63$ ( $\min : 16$, max:45); $86.5 \%$ of the women $(n=1942)$ were below 35 years while $13.5 \%(n=303)$ were above 35 years. Of the women, $36.5 \%(n=819)$ were detected to have urinary tract infection. $37.3 \%(n=725)$ of the women under the age of 35 had urinary tract infection while this rate was $31 \%(n=94)$ in those over the age of $35(p<0.05)$. Being pregnant below 35 years of age posed these women 1.3 times more at risk for urinary tract infection compared to non-pregnant women over $35(\mathrm{OR}=1.32 ; \mathrm{Cl}=1.02-1.72)$.

Conclusion: Urinary tract infection is one of the most important and most common diseases in pregnancy. Untreated infections have significant relationship with preterm labor and related complications. Urinary tract infections should be treated and not be overlooked during pregnancy.

Keywords: UTI, Pregnancy, Preterm labor 


\section{Giriş}

Üriner sistem enfeksiyonları gebelikte en sık görülen enfeksiyon hastalığıdır. Bu tanımlama ile üriner sistemin herhangi bir noktasında bakteri bulunması ve semptomlara sebep olması ifade edilmektedir. Bakteriüri idrarda bakteri mevcudiyetine verilen isimdir ve iki tipi bulunmaktadır. Asemptomatik bakteriüri denildiğinde eşlik eden herhangi bir semptom olmaksızın ard arda alınan iki idrar örneğinde $105 \mathrm{CFU} / \mathrm{ml}$ ya da daha çok bakteri üremesi olarak tanımlanır. Klinik açıdan anlamlı bakteriüri ise idrarda tek tip 106 $\mathrm{CFU} / \mathrm{ml}$ ya da daha çok bakteri saptanmasıdır. Piyelonefrit tanımı anlamlı bakteriüri ile birlikte böbrek kaliks, pelvis ve parankiminin inflamasyonudur. Sistit ise mesane mukoza inflamasyonu ile bakteriürinin birlikte olması halidir $(1,2)$. Üriner infeksiyon spektrumu geniş olup asemptomatik bakteriüriden pyelonefrite dek değişir. Gebelerde üriner enfeksiyonların görülme sıkIığını artıran çeşitli nedenler vardır. Bu duruma gebelerde görülen mekanik ve hormonal değişikliklerin zemin hazırladığı düşünülmektedir. Gebelik sürecinde üreter peristaltizmi önemli derecede azalır ve üreterler ve renal pelvisin dilate olmasına yol açar. Bu değişliklikler gebeliğin ilk haftalarında başlar ve doğuma kadar ilerler. Gebelikte idrar pH'sı artar; aminoasidüri ve glikozüri de ajan patojenlerin çoğalması için elverişli bir ortam oluşturur. Gebelikte asemptomatik bakteriüri insidansı \%4-7 arasında değişmektedir. Sosyoekonomik durumları iyi olan kadınlarda gebelikte bakteriüri insidansı sosyoekonomik durumu zayıf olanlara göre daha azdır. Bakteriüri görülme sıklığı; parite, yaş, kronik hastalık, cinsel aktivite, diabetes mellitus, orak hücre anemisi taşıyıcılığı ve üriner enfeksiyon öyküsü ile artar. Gebelerde üriner infeksiyonlarda görülen mikroorganizmalar gebe olmayan kadınlara benzer bulunmaktadır. Rutin idrar kültürlerinde tesbit edilen organizmaların birçoğu Escherichia coli, , Proteus mirabilis, Klebsiella gibi koliform bakterilerdir. Staphylococcus saprophyticus ve diğer koagülaz negatif stafilokoklara gebelikte az sayıda rastlanmasına karşın üriner sistem infeksiyonlarında ve taş oluşumu gibi komplikasyonların gelişmesinde önemli rolleri olduğu düşünülmek- tedir. Alt ve üst üriner sistem infeksiyonunun ayırıcı tanısında hastanın semptomları önemlidir. Sık idrara yapma, idrarda yanma gibi alt üriner sistem infeksiyonu bulgularına ateş, üşüme-titreme, yan ağrısı ve hassasiyeti, bulantı ve kusma gibi üst üriner sistem infeksiyonu belirtileri eşlik ediyorsa pyelonefrit akla gelmelidir (1). Gebelerde asemptomatik bakteriüri piyelonefriti arttıran bir risk faktörüdür ve asemptomatik bakteriüri ile preterm eylem ve düşük doğum ağırlığı arasında yakın ilişki mevcuttur. Gebelikte oluşabilecek olan idrar yolu enfeksiyonları (IYE) anne ve bebek sağığını tehdit edebilecek önemli sonuçlara neden olabileceği için bunların tedavi edilmesi olumlu sonuçlarla karşımıza gelecektir (3). Yapılan çeşitli çalışmalarda gebe kadınlarda iYE ve bakteriüri sıklık ve şiddetinin gebe olmayan kadınlardan daha fazla olduğu saptanmıştır. Öyle ki gebe kadınlarda piyelonefrite ilerleme riski \%40 a varan oranlarda yüksek bulunmuş ve bu kadınların preeklampsi, prematür doğum ve düşük doğum ağırlığı gibi sonuçlarla karşılaşma açısından da daha yüksek riske sahip olduğu saptanmıştır. Gebe kadınların üriner enfeksiyona yatkınlığının temelinde gebeliğe özgü fonksiyonel ve yapısal üriner yol değişiklikleri olduğu düşünülmüştür (4-10). Biz yaptığımız bu çalışmada kliniğimize başvuran gebe kadınlarda idrar yolu enfeksiyonu görülme sıklığını ve hangi mikroorganizmaların daha sık görüldüğünü araştırmayı amaçladık.

\section{GEREÇ ve YÖNTEM}

Bu çalışmaya Gaziosmanpaşa Üniversitesi Tıp Fakültesi Hastanesi Kadın Hastalıkları ve Doğum polikliniğine Ocak 2012 ve Haziran 2015 tarihleri arasında gebelik tanısıyla başvuran hastalardan 2245 hasta dahil edilmiştir. Hastaların sonuçları retrospektif olarak incelenmiştir. Hastaların test sonuçlarına hastane otomasyon sistemi üzerinden erişilmiştir. Tam idrar tetkiki hastanemiz biyokimya laboratuarında ve idrar kültürü analizleri hastanemiz mikrobiyoloji laboratuarında değerlendirilmiştir. Tetkik sonuçlarına otomasyon sistemi üzerinden retrospektif olarak ulaşılarak veriler elde edilmiştir. Veri analizleri IBM SPSS Statistics Version 20 istatistik paket progra- 
mı ve Open Epi programı kullanılarak yapılmıştır. Veriler sayı, yüzde ve ortalama standart sapmaları ile gösterilmiş, gruplar arası karşılaştırmalarda Ki-kare kullanılmıştır. İstatistiksel anlamlılık düzeyi $p<0.05$ olarak kabul edilmiştir.

\section{BULGULAR}

Çalışmaya alınan gebe hastaların $(n=2245)$ yaş ortalaması $28.0 \pm 5.63$ (min:16, maks:45) olup, $\% 86.5^{\prime} i$ ( $\left.n=1942\right) 35$ yaş altında, \%13.5'i $(n=303)$ 35 yaş ve üzerindedir. Hastaların \%36.5'inde ( $n=819$ ) gebelikte IYY saptanmıştır. 35 yaş altındaki hastaların \%37.3'ünde ( $n=725)$ iYE saptanırken, 35 yaş ve üzerindeki hastalarda bu oran \%31.0'dır $(n=94)(p<0.05) .35$ yaş altındaki gebeler IYE geçirme açısından, 35 yaş ve üzerindeki gebelere göre 1.3 kat daha riskli bulunmuştur $(\mathrm{OR}=1.32$; $\mathrm{Cl}=1.02-1.72$ ) (Tablo 1). Üç yıllık süreçte Kadın Hastalıkları ve Doğum polikliniğine başvuran hastalar arasında 2245 gebeden tam idrar tetkiki istenmiş olup, idrar tetkikinde 10 ve üzeri lökosit bulunan 819 gebenin 400'ünden idrar kültürü istenmiş ve bunların 34 tanesinde üreme tespit edilmiştir. Üreme tespit edilen idrar kültürlerinin üreyen bakterilere göre sayısı sırasıyla; $24 \mathrm{E}$. coli, 3 klebsiella, 2 proteus, 2 B grubu streptokok, 1 non-albicans candida, 1 enterokok, 1 candida albicans, 1 enterobakter olarak tespit edilmiştir.

\begin{tabular}{|c|c|c|c|c|c|}
\hline \multicolumn{6}{|c|}{ YAŞ VE IDRAR YOLU ENFEKSIYONU İLiŞKISi } \\
\hline \multirow{2}{*}{\multicolumn{3}{|c|}{$P<0.05$}} & \multicolumn{2}{|c|}{ IYE } & \multirow{3}{*}{$\begin{array}{c}\text { Total } \\
1942\end{array}$} \\
\hline & & & \multirow{2}{*}{$\begin{array}{c}\text { YOK } \\
1217\end{array}$} & \multirow{2}{*}{$\begin{array}{l}\text { VAR } \\
725\end{array}$} & \\
\hline \multirow{6}{*}{ YAŞ } & \multirow{3}{*}{$\begin{array}{l}<35 \\
\text { YAŞ }\end{array}$} & Sayı & & & \\
\hline & & \% (grup içi) & 62,7 & 37,3 & 100,0 \\
\hline & & $\%$ (tüm IYYE) & 85,3 & 88,5 & 86,5 \\
\hline & \multirow{3}{*}{$\begin{array}{l}\geq 35 \\
\text { YAŞ }\end{array}$} & Sayı & 209 & 94 & 303 \\
\hline & & \% (grup içi) & 69,0 & 31,0 & 100,0 \\
\hline & & \% (tüm iYE) & 14,7 & 11,5 & 13,5 \\
\hline \multirow{2}{*}{\multicolumn{2}{|c|}{ Total }} & Sayi & 1426 & 819 & 2245 \\
\hline & & \% (grup içi) & 63,5 & 36,5 & 100,0 \\
\hline
\end{tabular}

\section{TARTIŞMA}

Bu çalışma Tokat ili Gaziosmanpaşa Üniversite Hastanesi Kadın Hastalıkları ve Doğum po- likliniğine başvuran gebelerin idrar yolu enfeksiyonu sıklığını ve pozitif olan hastalarda etkeni belirlemek için yapılmıştır. 2012 Ocak ve Haziran 2015 döneminde hastaneye başvuran gebelerin \%36.5'inde $(n=819)$ gebelikte idrar yolu enfeksiyonu (IYE) olduğu saptanmıştır. İran Dezful şehrinde gebelerde yapılan bir çalışmada bu oran \%56.8 olarak bulunmuştur (11). Başka bir çalışmada, İran Bam şehrinde 1500 gebe ile yapılan bir çalışmada üriner sistem enfeksiyonu insidansı \%12.3 olarak tespit edilmiştir (12). Yine dünyanın farklı bölgelerinde yapılan çalışmalarda gebelerde üriner sistem enfeksiyon insidansları; Bookallil çalışması, Avustralya \%4.9 (13), Turpin çalışması, \%Gana 7.3 (14), Hernandez çalışması, Meksika \%8.4 (15) ve Tadesse çalışması Kuzeybatı Etiyopya \%9.8 (16) olarak tespit edilmiştir. Bu şehirlerde yapılan çalışmalardaki idrar yolu enfeksiyonu (IYE) bizim çalışmamıza göre oldukça düşük izlenmektedir. Bunun nedeni belirtilen şehirlerde hava sıcaklığının daha yüksek olmasına bağlı olarak bu insidansın düşmesi olabilir, yine bu hastaneler ve bizim hastanemizde kullanılan cihazların sensitivite farklılığı da bu duruma sebep olabilir. Elo ve ark. tarafından Finlandiya'da yapılan bir çalışmada hava sıcaklığınun iYE prevalansında çok önemli bir faktör olduğu tespit edilmiş, ve IYE yaz aylarında en düşük sıklıkta görülmekte iken en yüksek sıklıkta kış aylarında görülmüştür (19). Çalışmalar arasındaki sonuçsal farklılıkların bir diğer nedeni etnik ve sosyokültürel olarak farklı hasta gruplarının semptom gösterme ve tespit edilmesiyle ilişkili olabilir.

Çalışmaya alınan gebe hastaların $(n=2245)$ yaş ortalaması 28.0 \pm 5.63 (min:16, maks:45) olup, \%86.5 ( $n=1942)^{\prime} i \quad 35$ yaş altında, \%13.5 ( $\left.n=303\right)^{\prime} i$ 35 yaş ve üzerindedir. Amiri ve ark. yaptıkları çalışmada iYE geçiren hastaların büyük çoğunluğu 30 yaş üstünde ve iYE sıklığı en az görülen yaş aralığı 25-30 yaş arasıdır (11). Mobbasheri ve ark. yaptıkları çalışmada gebelerde IYE sıklığı en çok 35 yaş üstü kadınlarda tespit edilmiştir (17). Yine Al-Haddad ve ark. Yemen'de yaptıkları bir çalışmada gebelerdeki iYE sıklığı en çok 15-24 yaş aralığında görülmektedir (18). Görüldüğü üzere her çalışmada bu yaş aralığı oldukça farklılık göstermektedir ve iYE sıklığı ile yaş aralığı ilişkisini öngörmek mümkün görünmemektedir. 
Mevcut çalışma bulguları arasında Tokat şehrinde belirtilen tarihler arasında E.coli en sık IYE etkeni olarak karşımıza çıkmaktadır (\%70.5) ve Klebsiella ikinci etken olarak yer almaktadır (\%8.8). Amiri ve ark. çalışmasında da E.coli \%57.25 ve Klebsiella \%25.85 oranlarında en sık IYE etkeni olarak tespit edilmiştir (11). Yine Amiri ve ark. Babol'da yaptıkları bir taramada gebelerde en sık IYE etkeni olarak sırasıyla E.coli \%83, staphylococcus saprophyticus $\% 10$, enterokoklar $\% 4$ ve proteus $\% 3$ olarak tespit edilmiştir (20). Diğer tüm dünya genelinde yapılan çalışmalarda da E.coli iYE oluşmasında en sık karşılaşılan patojen olarak bulunmuştur ve Masinde, Tanzanya \% 47.2 (21), Al-Haddad, Yemen \% 41.5 (18) ve Hamdan, Sudan \% 42.4 olarak tespit edilmiştir (22). Bu çalışmalara bakıldığında Türkiye'de en sık iYE etkeni olan E.coli, Tokat için bir çok yere göre çok daha sık patojen olarak gözlemlenmektedir.

Sonuç olarak IYE gebelerde sık görülebilen bir enfeksiyon olup gebeliğe ait iYE kaynaklı olası komplikasyonları, morbiditeleri azaltmak amacı ile bu enfeksiyonun tespit, tedavi ve takibi dikkatle yapılmalıdır.

\section{KAYNAKLAR}

1. Uzun Ö. Gebelikte üriner sistem enfeksiyonları (Nasıl Tedav Edelim). Hacettepe Tıp Dergisi 2001;32:154-9.

2. Çolak H. Gebelik, doğum ve abortusla ilgili infeksiyonlar İnfeksiyon hastalıkları ve mikrobiyolojisi. Editörler: Topçu AW, Söyletir G, Doğanay M. İstanbul: Nobel Tıp Kitabevleri, syf. 2002;1:1089-101

3. Schneeberger $C^{1}$, Geerlings $\mathrm{SE}$, Middleton $\mathrm{P}$, Crowther $\mathrm{CA}$. Interventions for preventing recurrent urinary tract infection during pregnancy. Cochrane Database Syst Rev. $2015 \mathrm{Ju}$ 26;7:CD009279. doi: 10.1002/14651858.CD009279.pub3.

4. Schnarr J, Smaill F. Asymptomatic bacteriuria and symptomatic urinary tract infection in pregnancy. Eur J Clin Invest. 2008;38(Suppl. 2):50-7.

5. Farkash E, Wientraub AY, Sergienko R, et al. Acute antepartum pyelonephritis in pregnancy: a critical analysis of risk factors and outcomes. Eur J Obstet Gynecol Reprod Biol. 2012;162:24-7.

6. Gravett MG, Martin ET, Bernson JD, et al. Serious and lifethreatening pregnancy-related infections: opportunities to reduce the global burden. Plos Med. 2012;9:e1001324.

7. Foxman B. Epidemiology of urinary tract infections: incidence, morbidity, and economic costs. Am J Med. 2002;113:5-13.

8. Mazor-Dray E, Levy A, Schlaeffer F, Sheiner E. Maternal urinary tract infection: is it independently associated with adverse pregnancy outcome? J Matern Fetal Neonatal Med. 2009;22:12432.

9. Bolton $\mathrm{M}$, Horvath $\mathrm{DJ}$, Li B, et al. Intrauterine growth restriction is a direct consequence of localized maternal uropathogenic Escherichia coli cystitis. Plos ONE. 2012;7:1-9.

10. Jeyabalan A, Lain KY. Anatomic and functional changes of the upper urinary tract during pregnancy.Urol Clin North Am. 2007;34:1-6.

11. Amiri M, Lavasani Z, Norouzirad R, et al. Prevalence of Urinary Tract Infection Among Pregnant Women and its Complications in Their Newborns During the Birth in the Hospitals of Dezful City, Iran, 2012 - 2013. Iranian Red Crescent Medical Journal. 2015;17(8).

12. Soleimanizadeh LD, Basri N, Abaszadeh A, Arab M. Assessment of high risk pregnancy in Bam Mahdieh maternity hospital, 2002. J Shahrekord Univ Med Sci. 2004;6(2):67-73.
13. Bookallil $\mathrm{M}$, Chalmers $\mathrm{E}$, Andrew B. Challenges in preventing pyelonephritis in pregnant women in Indigenous communities. Rural Remote Health. 2005;5(3):395.

14. Turpin C, Minkah B, Danso K, Frimpong E. Asymptomatic bacteriuria in pregnant women attending antenatal clinic at Komfo Anokye teaching hospital, Kumasi, Ghana. Ghana Med J. 2007;41(1):26-9.

15. Hernandez Blas F, Lopez Carmona JM, Rodriguez Moctezuma JR, Peralta Pedrero ML, Rodriguez Gutierrez RS, Ortiz Aguirre AR. Asymptomatic bacteruiria frequency in pregnant women and uropathogen in vitro antimicrobial sensitivity. Ginecol Obstet Mex. 2007;75(6):325-31.

16. Tadesse A, Negash M, Ketema LS. Asymtomatic bacteriuria in pregnancy: assesment of prevlence, microbial agents and ther antimicrobial sensitivty pattern in Gondar Teaching Hospital, north west Ethiopia. Ethiop Med J. 2007;45(2):143-9.

17. Mobbasheri ET, Ghaemi E, Moujloo M, Vakili MA. [Prevalence of bacteriuria during pregnancy in Gorgan, Iran]. Gorgan Medical Journal. 2001;9:42-7.

18. Al-Haddad AM. Urinary tract infection among pregnant women in Al-Mukalla district, Yemen. East Mediterr Health J. 2005;11(3):505-10.

19. Elo J, Sarna S, Tallgren LG. Seasonal variations in the occurrence of urinary tract infections among children in an urban area in Finland. Ann Clin Res. 1979;11(3):101-6.

20. Yaghobi RH, Roshan AZPZ, Hajiahmadi M, Nasirim Amiri F. [The role of hygienic behavior in incidence of urinary tract infection among pregnant women referred to health center, Babol, 20032005]. J Babol Univ Med Sci. 2006;8(2):56-62.

21. Masinde A, Gumodoka B, Kilonzo A, Mshana SE. Prevalence of urinary tract infection among pregnant women at Bugando Medical Centre, Mwanza, Tanzania. Tanzan J Health Res. 2009;11(3):154-9.

22. Hamdan HZ, Ziad AH, Ali SK, Adam I. Epidemiology of urinary tract infections and antibiotics sensitivity among pregnant women at Khartoum North Hospital. Ann Clin Microbiol Antimicrob. 2011;10:2 